\title{
Antiasthmatic activity of 2-piperidone by selective animal models
}

\author{
Vani MAMILlAPAlLI 1,2* (D), Abdul Rahaman SHAIK ${ }^{3}$ (D), Prameela Rani AVUlA 4 (D) \\ 1 Department of Pharmacy, Research Scholar, Jawaharlal Nehru Technological University, Kakinada - 533003, East \\ Godavari (Dist.), Andhra Pradesh, India. \\ 2 Department of Pharmacognosy \& Phytochemistry, Faculty of Pharmacy, Vijaya Institute of Pharmaceutical Sciences \\ for Women, Enikepadu - 521108, Vijayawada, Krishna (Dist.), Andhra Pradesh, India. \\ 3 Department of Medicinal Chemistry, Faculty of Pharmacy, Nirmala College of Pharmacy, Atmakur, Mangalagiri - \\ 522503, Guntur (Dist.), Andhra Pradesh, India. \\ 4 Department of Pharmaceutics, Faculty of Pharmacy, Acharya Nagarjuna University, Nagarjuna Nagar - 522510, \\ Guntur (Dist.), Andhra Pradesh, India. \\ * Corresponding Author. Email: vanimamillapalli@yahoo.co.in (V.M.); Tel. +91-970-462 5782.
}

Received: 20 May 2019 / Revised: 28 December 2019 / Accepted: 03 February 2020

\begin{abstract}
: 2-piperidone is a six membered heterocyclic compound existing naturally in piperaceae and portulaceae families. The synthetic derivatives of piperidone are promising bioactive molecules. They are antioxidant and antiinflammatory agents. Antihistaminic and anticholinergic studies are used as a part of antiasthmatic study. In the current study antihistaminic and anticholinergic studies were carried out using guinea pig bronchi and ilei in naturally isolated compound 2-piperidone from the plant Talinum portulacifolium. The results indicate that the compound (2 mg/ kg 10.81 $\pm 1.29^{* * *}$ at $\mathrm{p}<0.001$ ) showed profound antihistaminic activity significantly in histamine induced bronchospasm model than standard drug chlorpheniramine $\left(2 \mathrm{mg} / \mathrm{kg} 8.77 \pm 0.43^{* *}\right.$ at $\left.{ }^{* *} \mathrm{p}<0.01\right)$. The compound can be further studied for antiasthmatic activity by various other ways to establish its mechanism of action as well as drug development studies to render it a novel antiasthmatic drug.
\end{abstract}

KEYWORDS: Antiasthmatic; bronchospasm; antihistaminic; 2-piperidone.

\section{INTRODUCTION}

Asthma is a chronic inflammatory and incurable illness of the lungs. It is characterised by tightness in the chest, breathlessness, wheezing, and coughing. The airways swell and become extremely sensitive to some of the substances a person might inhale. The increased sensitivity causes inflammation, tightening of the muscles which control airways leading to restriction, and further trigger an overproduction of mucus. A variety of immune cells, structure cells in the lung, cytokines, chemokines, adhesion molecules, and signaling pathways contribute to the asthmatic pathogenesis [1]. Presently, no full cure is available, management methods can help withstand the disease. The drugs currently available show poor symptomatic response with few side effects. Use of natural drugs is still common and wide spread all over the world. The pathogenesis of asthma is complex, and the use of herbals is also complicated with respect to the role as effective targets to alleviate it. Hence, separation of the effective constituents from herbals and study in terms of efficacy forms the general basic approach for the treatment of asthma [2].

Piperidine is one of the nitrogen containing six-membered heterocylic moiety, often found in naturally occurring bioactive compounds [3]. The compound 2-piperidone is a colourless liquid with pepper like smell, soluble in water and contains piperidine moiety. It is generally present in piperaceae family [4]. Piperine, the chief ingredient of Piper nigrum and other species of genus Piper belonging to piperaceae contains piperidine basic nucleus. It was studied for chemopreventive, antioxidant, immunomodulatory, stimulant, and hepatoprotective activities [5]. Recent investigations in humans revealed that piperine acts as an antiinflammatory and antiasthmatic drug [9]. But, it is not preferred pharmaceutically as it is less soluble in water, shows poor bioavalability and toxicity at higher concentration [7].

The synthetic derivatives of 3-piperidinone and 4-piperidinone were reported as febrifuge [8], antiviral [9], and cytotoxic agents [10]. The piperidinone chemical moiety is used mostly as an intermediate in the

How to cite this article: Vani M, Addul Rahaman S, Prameela Rani A. Antiasthmatic activity of 2-piperidone by selective animal models. J Res Pharm. 2020; 24(3): 334-340. 
manufacturing of pharmaceuticals [11]. The application of it as therapeutic agent is less prominent and needs to be studied for a range of pharmacological activities. It was also found to be present in Talinum portulacifolium of portulacaceae, [12] and studied for hepatoprotective activity [13]. As there were no literature reports available on antihistaminc and anticholinergic activities of naturally isolated single moiety 2-piperidinone, the current investigation was planned to carry out the antiasthmatic studies by histamine, acetylcholine induced bronchospasm and ileum contraction models.

\section{RESULTS AND DISCUSSION}

\subsection{Acute toxicity study}

The results of acute toxicity study revealed that isolated compound TPC (2-piperidone) was safe up to $50-3000 \mathrm{mg} / \mathrm{kg}$ when administered orally in guinea pigs. After $24 \mathrm{hrs}$, the animals were found to be well tolerated, safe with no signs of mortality and toxicity. Hence a safe and therapeutically effective dose of 2 $\mathrm{mg} / \mathrm{kg}$ treatment was chosen for animal studies.

\subsection{Histamine and acetylcholine induced bronchospasm study}

\subsubsection{Histamine - induced bronchospasm}

The compound TPC offered protection against bronchospasm induced by histamine as compared to control. It significantly increased the time of onset of PCT following exposure to histamine $\left({ }^{* * *} \mathrm{p}<0.001\right)$ aerosol-induced bronchospasm in guinea pigs (Table 1). The standard drug chlorpheniramine showed significant PCT 8.77 at $2 \mathrm{mg} / \mathrm{kg}\left({ }^{* *} \mathrm{p}<0.01\right)$. TPC showed an increase in PCT $10.82\left({ }^{* * *} \mathrm{p}<0.001\right)$ (Table 1). It exhibited profound antihistaminic activity than standard chlorpheniramine.

Table 1. Effect of histamine - induced bronchospasm.

\begin{tabular}{ccc}
\hline Groups & Drug and Dose & PCT Mean \pm SEM \\
\hline Control & Distilled water p.o. & $2.22 \pm 0.24$ \\
Standard & Chlorpheniramine $2 \mathrm{mg} / \mathrm{kg}$ p.o. & $8.77 \pm 0.43^{* *}$ \\
Test & TPC $2 \mathrm{mg} / \mathrm{kg}$ p.o. & $10.81 \pm 1.29^{* * *}$ \\
\hline
\end{tabular}

${ }^{a}$ Each value was expressed as mean \pm SEM, where $n=4$ in each group.

${ }^{b *} \mathrm{p}<0.05,{ }^{* *} \mathrm{p}<0.01,{ }^{* * *} \mathrm{p}<0.001$ compared to control by one-way ANOVA, Tukey's test.

c TPC indicates 2-piperidone

\subsubsection{Acetylcholine - induced bronchospasm}

The results of the study were comparable to standard drug atropine sulfate which exhibited PCT 11.60. TPC has shown anticholinergic activity with an increased PCT $\left.{ }^{* * *} \mathrm{p}<0.001\right)$ and offered protection against acetylcholine induced bronchospasm (Table 2).

Table 2. Effect of acetylcholine - induced bronchospasm.

\begin{tabular}{lcc}
\hline Groups & Drug and Dose & PCT Mean \pm SEM \\
\hline Control & Distilled water p.o. & $3.22 \pm 0.60$ \\
Standard & Atropine sulphate $2 \mathrm{mg} / \mathrm{kg}$ p.o. & $11.60 \pm 1.24$ \\
Test & TPC $2 \mathrm{mg} / \mathrm{kg}$ p.o. & $10.31 \pm 2.12^{* * *}$ \\
\hline \multicolumn{3}{c}{ a Each value was expressed as mean \pm SEM, where $\mathrm{n}=4$ in each group. } \\
${ }^{\mathrm{b} *}{ }^{*}<0.05,{ }^{* *} \mathrm{p}<0.01,{ }^{* * *} \mathrm{p}<0.001$ compared to control by one-way ANOVA, Tukey's test. \\
${ }^{c}$ TPC indicates 2-piperidone.
\end{tabular}

\subsection{Histamine and acetylcholine induced ileum contraction study}

\subsubsection{Histamine - induced ileum contraction}

The compound TPC inhibited the contraction induced by histamine in isolated guinea pig ileum studies (*** $\mathrm{p}<0.001)$. It exhibited meaningful antihistaminic activity compared to control. The standard drug chlorpheniramine produced response 1.8 with $63.3 \%$ inhibition $\left({ }^{*} \mathrm{p}<0.05\right)$. TPC showed $66.6 \%$ inhibition ${ }^{* * *}$ $\mathrm{p}<0.001$ ) (Table 3). It exhibited better inhibition of ileum contraction than standard. 


\title{
2.3.2. Acetylcholine - induced ileum contraction
}

TPC inhibited the contraction induced by acetylcholine as compared to control significantly $\left({ }^{*} \mathrm{p}<0.05, * *\right.$ $\left.\mathrm{p}<0.01,{ }^{* * *} \mathrm{p}<0.001\right)$. The standard drug atropine sulphate exhibited response 2.2 with $60 \%$ inhibition $\left({ }^{*} \mathrm{p}<0.05\right)$. TPC showed response 3.7 with $17.77 \%\left({ }^{*} \mathrm{p}<0.05\right)$ inhibition. The standard drug atropine sulphate exhibited more inhibition than test group (Table 4$)$.

Table 3. Effect of histamine - induced ileum contraction.

\begin{tabular}{llll}
\hline Groups & Drug and Dose & $\begin{array}{l}\text { Response } \\
\text { Mean } \pm \text { SEM }\end{array}$ & \% Inhibition \\
\hline Control & Histamine 0.5 mg & $4.9 \pm 0.08$ & $0 \%$ \\
Standard & Chlorpheniramine $0.5 \mathrm{mg}$ & $1.8 \pm 0.91$ & $63.3 \%$ \\
Test & TPC 0.5 $\mathrm{mg}$ & $1.8 \pm 0.34^{* * *}$ & $66.6 \%$ \\
\hline
\end{tabular}

a Each value was expressed as mean $\pm \mathrm{SEM}$, where $\mathrm{n}=4$ in each group.

${ }^{b *} p<0.05,{ }^{* *} p<0.01,{ }^{* * *} p<0.001$ compared to control by one-way ANOVA, Tukey's test.

c TPC indicates 2-piperidone.

Table 4. Effect of acetylcholine - induced ileum contraction

\begin{tabular}{cccc}
\hline Groups & Drug and Dose & $\begin{array}{c}\text { Response } \\
\text { Mean } \pm \text { SEM }\end{array}$ & \% Inhibition \\
\hline Control & Acetylcholine 0.1 mg & $5.5 \pm 0.27$ & $0 \%$ \\
Standard & Atropine sulphate 0.5 mg & $2.2 \pm 0.81$ & $60 \%$ \\
Test & TPC 0.5 mg & $3.7 \pm 0.15^{*}$ & $17.77 \%$ \\
\hline
\end{tabular}

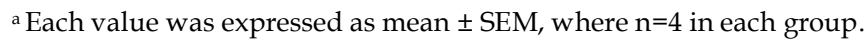

${ }^{b *}{ }^{2}<0.05,{ }^{* *} p<0.01,{ }^{* * *} p<0.001$ compared to control by one-way ANOVA, Tukey's test.

c TPC indicates 2-piperidone.

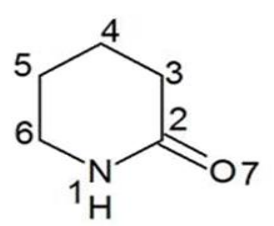

\begin{abstract}
Structural analysis: UV absorbance 322nm, 0.01\% w/v, brown liquid (U-2900/U-2910, UV-visible double beam spectrophotometer, Lab 294 India). IR, Vmax cm$~^{-1} 3311.43$ - (N-H str); 1621.67 - (C=O str); 2948.65, 2872.75 - (C-H str); 1494.38, 1409.04 (C-N 295 str). APCI-MS (m/z; \%): $199.1(2 \mathrm{M}+\mathrm{H}+; 15)$ 100.2 (M+H+; 100) (IFS 66v/s vacuum FT-IR, Bruker optics). 1H NMR, 296 (in ppm); $\delta=4.79(\mathrm{~S}, 1 \mathrm{H}, \mathrm{NH}) ; \delta=2.30$ (t, J=6.4 Hz, 2H, H-6); $\delta=1.76(\mathrm{~m}, 4 \mathrm{H}, \mathrm{H}-4$ \& H-5) $\delta=3.27$ (t, $\mathrm{J}=5.7 \mathrm{~Hz}, 2 \mathrm{H}, \mathrm{H}-297$ 3); 13CNMR (CDCl3) (in ppm); $\delta=173(\mathrm{C}=\mathrm{O}) ; \delta=41.61$ (C-3); $\delta=21.76$ (C-4); $\delta=20.40$ (C-5) $\delta=30.72$ (C6); (Oxford 29860 and $90 \mathrm{MHz} N M R), \mathrm{CDCl}_{3}$ (Deuterated chloroform) as solvent [13].
\end{abstract}

Figure 1. Structure of 2-piperidone.

During allergy immunoglobulin-E mediated mast cells get activated and release inflammatory mediators like interleukins, eosinophils, neutrophils, histamines, bradykines that cause inflammation in the throat and hyper secretion in bronchi [14]. Histamine is one of the important mediators of broncho constriction and inflammation present in mast cells, and varius body fluids. It participates in various cell physiological processes like allergic reaction, inflammation, gastric acid secretion, central and peripheral neuro transmission [15]. Histamine release from mast cells and basophils by antigenic stimulation causes smooth muscle contraction, increased vascular permeability, and mucus formation by stimulation of $\mathrm{H} 1$ receptors, a common feature of asthma. Hence, use of antihistamines is a part of antiallergic therapy.

Apart from it parasympathetic nerves which release acetylcholine as neuro transmitter also control the symptoms and inflammation of allergic diseases through peripheral muscarinic receptors which are present on air way smooth muscles and secretory glands. So, muscarinic antagonists are also used in the treatment of asthma [16]. Therefore the drugs which block the affects of inflammatory mediators like histamine, acetylcholine are used in the treatment of asthma. Antiasthmatic drugs act on the contraction of the ileum muscle through several mechanisms, including stimulation of $\beta$-adrenergic receptors, inhibition of histamine (H1) receptors, or through an anticholinergic property $[17,18]$. Hence, use of natural drugs with antioxidant, immune modulatory and anti-inflammatory properties would be beneficial. The excessive generation of 
reactive oxygen species (ROS) induced by various stimuli and which exceeds the antioxidant capacity of the organism leads to variety of pathophysiological processes such as inflammation, diabetes, genotoxicity and cancer [19]. Piperidone compounds are used as antioxidants [5].

The compound 2-piperidone increased PCT through dilatation of the bronchial smooth muscles more against histamine than acetylcholine. Further, there was more inhibition of histamine-induced ileum contraction supporting $\mathrm{H} 1$ receptor antagonistic activity. The compound may act as bronchodilator by opposing histaminergic receptors (Table 1). The support to the H1 receptor antagonistic activity of TPC can be attributed to the literature reports on antihistaminic activities of phenyl substituted piperidone moiety as part of their structure [20]. Li et al., [21] synthesized compounds containing 2-piperidone as structural moiety and evaluated them for alzheimer's disease, and inflammation. It was reported that the derivatives showed potent activity against alzheimer's disease and could inhibit inflammatory cytokins. De Meglio et al., [20] prepared oxatomide derivatives using piperidone moiety, examined the antihistaminic activity and revealed that the derivatives showed activity similar to oxatomide The antihistaminic bronchodilator effect exhibited by TPC was in line with the findings of antihistaminic activity of pulegone in guinea pig ileum [22, 20].

\section{CONCLUSION}

2-Piperidone acted as a bronchodilator in both histaminic and cholinergic studies. It opposed ileum contractions induced by histamine better than acetylcholine. Hence, further studies can be carried out through other models of study, in order to develop it as better bronchodilator to overcome current clinical problems in the treatment of asthma.

\section{MATERIALS AND METHODS}

\subsection{Chemicals}

The compound 2-piperidone (Figure 1), was isolated from the plant Talinum portulacifolium. The other chemicals used in the study were supplied from MERCK, India. All the chemicals and reagents used were of analytical grade.

\subsection{Experimental animals}

Guinea pigs (200 - $600 \mathrm{~g}$ ) of either sex for carrying out antiasthmatic activity were purchased from Mahaveer enterprises, Hyderabad, Telangana, India, housed in standard conditions of temperature $\left(22 \pm 2^{\circ} \mathrm{C}\right)$, relative humidity $(55 \pm 5 \%)$, and light (12 h light/dark cycles). They were fed with standard pellet diet and water ad libitum. The experimental protocol was approved by the Institutional Animal Ethical Committee (IAEC) of Nirmala College of Pharmacy, Atmakur, Mangalagiri, Guntur district, Andhra Pradesh, India, approval no 012/IAEC/NCPA/PhD/2016-17, nominated by Committee for the Purpose of Control and Supervision of Experiments on Animals (CPCSEA), Ministry of Environment and Forests, Department of Animal Welfare, Government of India.

\subsection{Acute toxicity testing}

The animals were overnight fasted prior to the experiment. Different doses (50-3000 mg/ $\mathrm{kg}$, orally) of the isolated compound were administered to groups of guinea pigs. The animals were observed continuously for $1 \mathrm{~h}$, next half-hourly intervals for $4 \mathrm{~h}$ for any gross changes in their behavior and then up to $24 \mathrm{~h}$ for any mortality as per the Organization for Economic Co-Operation and Development (OECD) guidelines 425 [23].

\subsection{Histamine and acetyl choline induced bronchospasm study}

Guinea pigs of either sex of body weight 200 - $500 \mathrm{~g}$ were divided into three groups separately to carry out histamine and acetylcholine induced bronchospasm model studies. Each group comprised of four animals. Animals were exposed to $0.1 \% \mathrm{w} / \mathrm{v}$ of histamine dihydrochloride aerosol in a histamine chamber (Sigma Scientific). They were also exposed to $0.5 \%$ acetylcholine chloride aerosol separately. Progressive dyspnoea was observed in animals when exposed to both the aerosols. Preconvulsion time (PCT) was determined from the time of aerosol exposure to the onset of dyspnoea leading to the appearance of convulsions on day $0\left(\mathrm{~T}_{1}\right)$. As soon as dyspnoea commenced, the animals were removed from the chamber and placed in fresh air. Test group animals were given isolated compound at a dose of $2 \mathrm{mg} / \mathrm{kg}$ orally (p.o.) once a day for 7 days at the volume of $2.4 \mathrm{ml} / \mathrm{kg}$ to histamine induced group. The acetylcholine induced group received TPC at the volume of $2.7 \mathrm{ml} / \mathrm{kg}$. The standard group studied for antihistaminic activity received chlorpheniramine at the volume of $3 \mathrm{ml} / \mathrm{kg}$. The standard animal group studied for anticholinergic activity received atropine sulphate 
at the volume of $2.7 \mathrm{ml} / \mathrm{kg}$. The stock solution of all the drugs was prepared in distilled water [23, 25]. On the seventh day, $2 \mathrm{~h}$ after the last dose, PCT was recorded $\left(\mathrm{T}_{2}\right)$ [21].

The percentage increase in time of PCT was calculated using the following formula (Equation 1):

Percentage increase in $P C T=\left(1-\frac{T 1}{T 2}\right) \times 100$

Where $T_{1}$ is PCT on day 0 and $T_{2}$ is PCT on day 7.

\subsubsection{Histamine - induced bronchospasm}

Group-1: Control group animals received distilled water

Group-2: Standard group animals received chlorpheniraminemaleate

Group-3: Test group animals received 2-piperidone isolated from T. portulacifolium (TPC) (Table 1).

\subsubsection{Acetylcholine - induced bronchospasm}

Group-1: Control group animals received distilled water

Group-2: Standard group animals received atropine sulphate

Group-3: Test group animals received 2-piperidone isolated from T. portulacifolium (TPC) (Table 2).

\subsubsection{Statistical analysis}

The experimental data was expresed as a mean \pm Standard error of the mean (SEM) and analyzed statistically using One-way analysis of variance (ANOVA), followed by Tukey's test, compared with control to find out the level of significance.

\subsection{Histamine and acetylcholine induced ileum contaction study}

Guinea pigs of body weight 200-500 g were selected, divided into three groups separately to carry out histamine and acetylcholine induced ileum contraction model studies. They were allowed to starve overnight with free access to water. The animals were killed by a blow on the head and exsanguinated. The ileum was isolated, cut into individual sections of $1 \mathrm{~cm}$, and divided into three groups; each group consisted of four ileums [24].The isolated ileum was mounted in a $30 \mathrm{ml}$ organ bath (Lab Tree India) containing tyrode solution, maintained at $37 \pm 1{ }^{\circ} \mathrm{C}$, and gassed with air. The tissue was equilibrated for 45 min during which the bath solution was replaced every $10 \mathrm{~min}$. A drug tissue contact time of $1 \mathrm{~min}$ was maintained and $15 \mathrm{~min}$ time cycle was followed. The concentrations ranging from $0.1-0.5 \mathrm{mg}$ were prepared from stock solution of $1 \mathrm{mg} / \mathrm{ml}$ and tested to obtain dose response curves. The concentration at which maximum dose response obtained was chosen for the study $[25,26]$. After obtaining a maximal dose response curve of histamine and acetyl choline, the isolated compound $(0.5 \mathrm{mg})$ was added to the reservoir seperately. Histamine $(0.5 \mathrm{mg})$ and acetyl choline $(0.1 \mathrm{mg})$ were given repeatedly in the presence of isolated compound TPC $[25,26]$.

\subsubsection{Histamine- induced guinea pig ileum contraction}

Group-1: Control group animals received histamine

Group-2: Standard group animals received chlorpheniramine

Group-3: Test group animals received 2-piperidone isolated from T.portulacifolium (TPC) (Table 3).

\subsubsection{Acetylcholine - induced guinea pig ileum contraction}

Group-1: Control group animals received acetylcholine

Group-2: Standard group animals received atropine sulphate

Group-3: Test group animals received 2-piperidone isolated from T.portulacifolium (TPC) (Table 4)

\subsubsection{Statistical analysis}

The results of the study were expressed as mean \pm SEM and analyzed statistically using One-way Analysis of Variance (ANOVA) followed by Dunnett's test for individual comparison of groups with control. Data were considered statistically significant at ${ }^{*} \mathrm{P}<0.05$ and ${ }^{* *} \mathrm{P}<0.01$ respectively. 
Acknowledgements: The authors are thankful to department of Pharmacy, Jawaharlal Nehru Technological University, Kakinada, East Godavari (Dist.), A.P., India, department of Pharmacognosy and Phytochemistry, department of Pharmacology, Vijaya Institute of Pharmaceutical Sciences for Women, Enikepadu, Vijayawada, Krishna (Dist.), A.P., India, deprtment of Medicinal Chemistry, Nirmala college of Pharmacy, Atmakur, Mangalagiri, Guntur (Dist.), A.P., India, department of Pharmaceutics, Acharya Nagarjuna University, Nagarjuna Nagar, Guntur (Dist.), A.P., India for their kind encouragement and support.

Author contributions: Concept - Sk. A. R.; Design - M.V., Sk. A. R., A. P. R.; Supervision - A. P. R.; Resources - M.V.; Materials - M.V., Sk. A. R., A. P. R.; Data Collection and/or Processing - M.V., Sk. A. R.; Analysis and /or Interpretation - M.V., Sk. A. R.; Literature Search - M.V., Sk. A. R., A. P. R.; Writing - M.V.; Critical Reviews - M.V., Sk. A. R., A. P. R.

Conflict of interest statement: The authors declared no conflicts of interests in the manuscript.

Ethics committee approval: The experimental protocol was approved by the Institutional Animal Ethical Committee (IAEC) of Nirmala College of Pharmacy, Atmakur, Mangalagiri, Guntur district, Andhra Pradesh, India, approval no 012/IAEC/NCPA/PhD/2016-17, nominated by Committee for the Purpose of Control and Supervision of Experiments on Animals (CPCSEA), Ministry of Environment and Forests, Department of Animal Welfare, Government of India.

\section{REFERENCES}

[1] Broide D H. Molecular and cellular mechanisms of allergic disease. J Allergy Clin Immunol. 2001; 108(2): S65-S71. [CrossRef]

[2] Ward C E, Baptist A P. Characteristics of Complementary and Alternative Medicine (CAM) use among older adults with asthma. J Asthma. 2016; 53(5): 546-552. [CrossRef]

[3] Taniguchi $\mathrm{T}$ and Ogasawara K. A diastereocontrolled synthesis of (+)-febrifugine: A potent antimalarial piperidine alkaloid. Org Lett. 2000. 2(20): 3193-3195. [CrossRef]

[4] Maedeh Mohammadi, Ghasem D. Najafpour, Maryam Nikzad. Piperine-The Bioactive Compound of Black Pepper: From Isolation to Medicinal Formulations. Compr Rev Food Sci F. 2017; 16: 124-140. [CrossRef]

[5] Darshan S, Doreswamy R. Patented anti-inflammatory plant drug development from traditional medicine. Phytother Res. 2004; 18: 343-357. [CrossRef]

[6] Meghwal M, Goswami T. Piper nigrum and piperine: An update. Phytother Res. 2013; 27: 1121-1130. [CrossRef]

[7] Pachauri M, Gupta ED, Ghosh PC. Piperine loaded PEG-PLGA nanoparticles: preparation, characterization, and targeted delivery for adjuvant breast cancer chemotherapy. J Drug Delivery Sci Technol. 2015; 29: 269-282. [CrossRef]

[8] Takeuchi Y, Azuma K, Takakura K, Abe H, and Harayama T. Asymmetric synthesis of febrifugine and isofebrifugine using yeast reduction. ChemComm. 2001; 17: 1643-1644. [CrossRef]

[9] El-Subbagh H I, Abu-Zaid S M, Mahran M A, Badria F A, Al-Obaid A M. Synthesis and biological evaluation of certain $\alpha, \beta$-unsaturated ketones and their corresponding fused pyridines as antiviral and cytotoxic agents. J Med Chem. 2000; 43(15): 2915-2921. [CrossRef]

[10] Venkatesa Perumal R, Adiraj M, and Shanmuga Pandiyan P. Synthesis, analgesic and anti inflammatory evaluation of substituted 4-piperidones. Indian Drugs. 2001; 38(3): 156-159.

[11] Koh PF, Wang P, Huang JM, Loh TP. Biomass derived furfural-based facile synthesis of protected (2S)-phenyl-3piperidone, a common intermediate for many drugs. ChemComm. 2014; 50 (61): 8324-8327. [CrossRef]

[12] Vani M, Abdul Rahaman Sk, Prameela Rani A. In vitro, in vivo Anti-Asthmatic Studies of Talinum portulacifolium $F$ Asian J Pharm. 2017; 11(2): S289-S301.

[13] Vani M, Abdul Rahaman Sk, Prameela Rani A. Hepatoprotective studies of 2-piperidone isolated from leaf extracts of Talinum portulacifolium (Forssk.) Asch. ex Schweinf in CCl4 induced hepatotoxicity. J Pharm Pharmacogn Res. 2019; 7(4): 234-245.

[14] Sagar R, Sahoo HB, Kar B, Mishra NK, Mohapatra R, Sarangi SP. Pharmacological evaluation of Calendula officinalis L. on bronchial asthma in various experimental animals. Int J Nutr Pharmacol Neurol Dis. 2014; 4(2): 95-103. [CrossRef]

[15] Goyal RK, Practical in Pharmacology, third ed., B.S. Shah Prakashan, India, 2003.

[16] Kubo N, Minami T, Hori Y, Yamashita T, Kumazawa T. Enhanced parasympathetic nerve activities in experimentally induced nasal hyper sensitivity. Acta Otolaryngol Suppl. 1989; 463: 14-20. [CrossRef]

[17] Stephen OO, Gerald IE, Ifeanyi HA, Ogochukwu LI, Dickson OU, Viona O. Evaluation of the anti-asthma activity of aqueous root bark extract of Ficus exasperata Vahl (Moraceae). Int J Health Res. 2012; 5: 5-12 
[18] Sagar R, Sahoo H B. Evaluation of the antiasthmatic activity of ethanolic extract of Elephantopus scaber L. leaves. Indian J Pharmacol. 2012; 44: 398-401. [CrossRef]

[19] Mc Clements J, Decker EA. Lipid oxidation in oil-in-water emulsions: Impact of molecular environment on chemical reactions in heterogeneous food systems. J Food Sci. 2000; 65: 1270. [CrossRef]

[20] De Meglio PG, Corradi F, Ravenna F, Gentili P, Tempra-Gabbiati G, Cristina T, Riva M. Pyrrolidone and piperidone derivatives with antihistaminic and antianaphylactic activities, Synthesis and pharmacological study. Chem Inform. 1987; 42(5): 359-82. [CrossRef]

[21] Li L, Chen M, Jiang FC. Design, synthesis, and evaluation of 2-piperidone derivatives for the inhibition of $\beta$-amyloid aggregation and inflammation mediated neurotoxicity. Bio org Med Chem. 2016; 24(8): 1853-1865. [CrossRef]

[22] Ortiz de Urbina AV, Martin ML, Montero MJ, Carron R, Sevilla MA, San Roman L. Antihistaminic activity of pulegone on the guinea-pig ileum. J Pharm Pharmacol. 1990; 42(4): 295-296. [CrossRef]

[23] OECD guidelines for the testing of chemicals-425. Acute oral toxicity-up and down procedure (UDP) 2008. http://www.oecd.org (accessed on 25 December 2019). [CrossRef]

[24] Chandrakant Nimgulkar C, Dattatray Patil S, Dinesh Kumar B. Anti-asthmatic and anti-anaphylactic activities of Blatta orientalis mother tincture. Homeopathy. 2011; 100: 138-143.

[25] Erhirhie EO, Ekene NE, Ajaghaku DL. Guidelines on dosage calculation and stock solution preparation in experimental animal studies. J Nat Sci Res. 2014; 4(18): 100-106.

[26] OECD GD 24 Guidance document on Acute Oral Toxicity. Environmental Health and Safety Monograph Series on Testing and Assessment. 2000. http:/ / www.oecd.org (accessed on 25 December 2019). [CrossRef]

This is an open access article which is publicly available on our journal's website under Institutional Repository at http://dspace.marmara.edu.tr. 